\title{
In Academic Research
}

from the Association of College and Research Libraries Research and Scholarly Environment Committee (ACRL ReSEC)

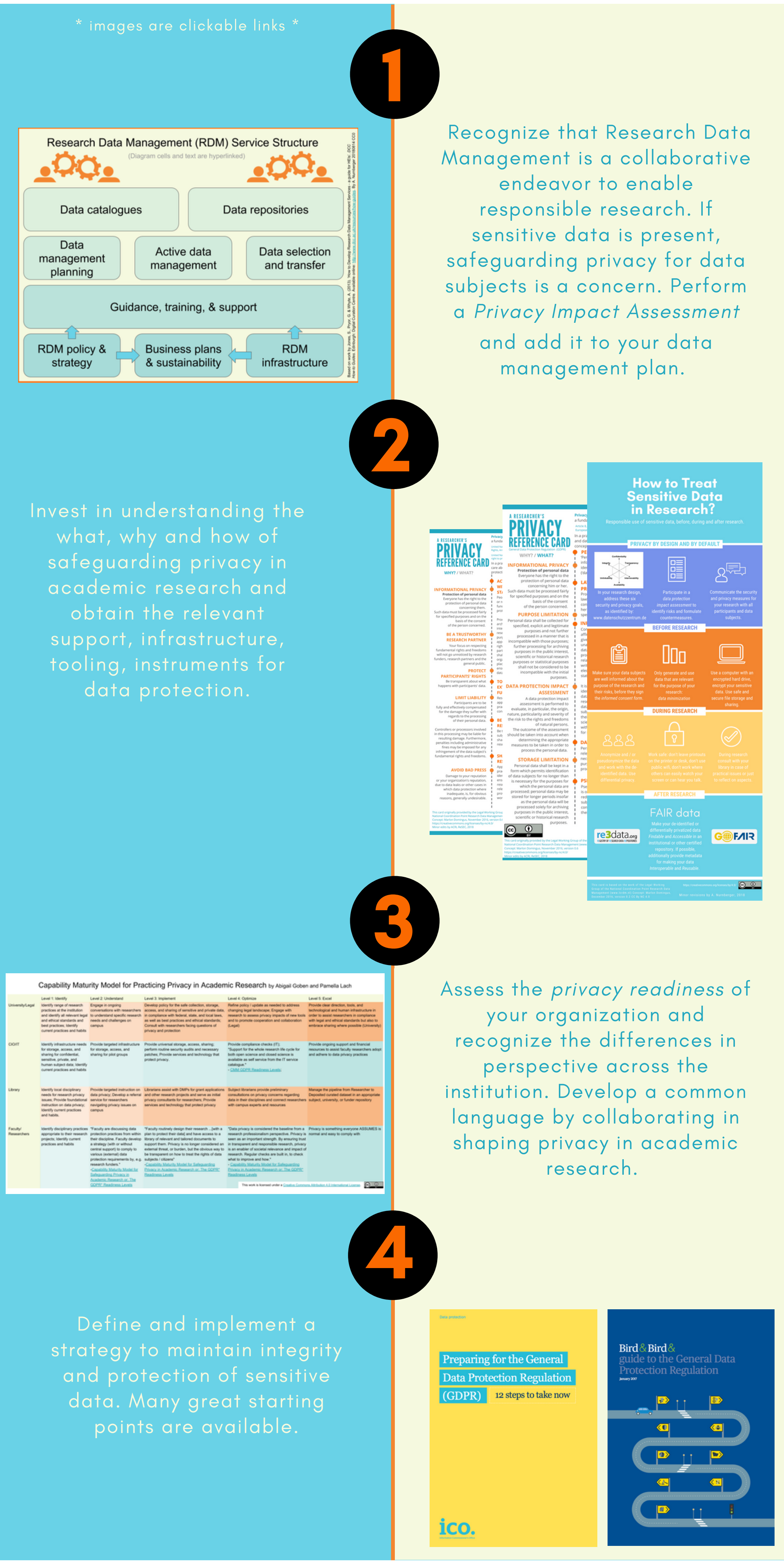

